\title{
Theatre Arts as Social Marketing Application Tool: Sustainable Development Approach to Diffuse the Environmental Message to Teenagers in Chiang Mai, Thailand
}

\author{
Kitt Wongarsa, Sirithorn Siriwan \\ Chiang Mai University, Chiang Mai, Thailand
}

\begin{abstract}
Often, the word "community" and "sustainability" are interlinked in 21st century development approaches. Most development communicators have focused on top-down communication strategies and used various means to diffuse the message to the target community. However, with the change in media landscape today, the challenge is how to select the "right" communication application to foster the behavioral and cognitive sustainable changes in their own community. This research aims to investigate theatrical performance as sustainable communicative means demonstrating environmental issues and the concepts of sustainable development among high school students and Chiang Mai University students. With the application of "Devised Theatre", the process provides a space to investigate the attributes, characteristics and development of community theatre on how it reflects the concept of communication for social change. The research, therefore, examines the outcome of this creative social application tool and utilizes Practice as Research $(\mathrm{PaR})$ a research methodology. The result will reveal the following: (1) how dramatic arts can be an effective means of social marketing to raise "awareness" on environmental issues; (2) how the performance raises environmental awareness in not only physical and psychological phases, but also spiritual dimension as a learning process among the participants, and (3) the sustainability of theatrical social application tool in which the participants of devised theatre project (devisees) can become the devisors in order to form new generation of the devisees - the teenage audience.
\end{abstract}

Keywords: theatre, social change, social marketing, participatory communication, practiceas research, sustainable development, environmental communication

\section{Introduction}

"Social Marketing" is a concept being employed widely in the 1970s by Kotler and Zaltman (Dinan \& Sargeant, 2000), which tries to insert the "ideas" of products and services to the target market. That point became the initial idea of how to insert social idea to change the customer's behavior onto social issues as well as how we call "social idea". Social marketing, hence, can be regarded as the methodology related to the notion of Dependency Paradigm. This conceptualization became the next logical phase from the diffusion theories. Later in 1970s the integrated concept of marketing and society emphasized on the challenges of the change of values, knowledge and behavior of target audience. The recent trend in Social Marketing is to combine Social

Kitt Wongarsa, Ph.D., Lecturer, Faculty of Mass Communication, Chiang Mai University. Sirithorn Siriwan, Lecturer, Faculty of Mass Communication, Chiang Mai University. 
Marketing with the community through media campaigns. This shift began to focus the change in the mind rather than the behavioral change while Entertainment-Education is known as the adaptation of using existing communication channels with local belief systems adapted by Social Marketing.

This research attempts to project social marketing as one approach for finding sustainable solutions to many environmental problems currently facing the global community. The social marketing approach applies participatory communication and media concept to diffuse environmental information campaigns.

According to Maibach (1993), social marketing principles include adoption of a consumer orientation, mutual exchange between marketer and audience, analysis and segmentation of the audience, establishment of appropriate and realistic campaign objectives, application of formative research, analysis of channels of communication, use of behavioral theory, the creation of a marketing mix, application of process and outcome evaluation strategies, communication at the macro-social level, and establishing a time frame that facilitates institutionalization of the campaign goals. Attention to these principles will help campaign and policy planners translate growing environmental concern among the populations and governments of the world into effective environmental action.

The definition of Social Marketing has been broadened and described as the application of commercial marketing technologies to analyze, design, execute, and evaluate the programs designed to influence the voluntary behavior of target audience in order to improve their personal well-beings and that of their society (Andreason, 1995).

Much of criticism towards Social Marketing is that it tends to pay too much attention on behavioral change. Social Marketing tends to intentionally direct people rather than guide them because it is firmly rooted in marketing and treats people as the consumers or targets rather than beneficiaries. Most importantly, it focuses on the individual's cutting through social structures and tends to persuade people to engage in behaviors that are predetermined by different interest group and not the people themselves (Beltran, 1976).

In the late1970s, the idea of using television as an instructional/development medium appealed to both administrators and development experts because of its immense potential in propagating useful ideas and practices. Entertainment-education (EE) is the process of purposely designing and implementing media messages in both entertaining and educational modes in order to foster audience's knowledge on educational issues, creating favorable attitudes, and changing overt behavior. This strategy uses universal appeal of entertainment to show individuals how they can live safer, healthier, and happier lives ${ }^{1}$ (Singhal \& Rogers, 1999).

According to Singhal and Rogers (1988), pro-development soap operas in Mexico promoted knowledge and values to the viewing audience so that these individuals could have better understanding about the reality of their social problems, and seek possible solutions. Following the example of Mexico and spurred by the efforts of Population Communications International (PCI), the Indian television authority experimented with Hum Log (1984-85), a soap opera dealing with social problems in contemporary Indian society. On the one hand, the major advantage of Entertainment-Education is that the programs with educational content do not need to be dull and uninteresting but they would rather integrate formats that promote pro-social behavior (Waisbord,

\footnotetext{
${ }^{1}$ Singhal and Rogers (1999) also pointed out that entertainment-education programs facilitate social change as followed: (1) At the individual level by influencing awareness, attention and behavior toward a socially desirable objective; and (2) At the larger community level of the individual audience member by serving as an agenda setter,or influencing public initiatives in a socially desirable direction.
} 
2000). On the other hand, Entertainment-Education faced major issues on both practical and theory backgrounds. Papa et al. (2000) points out three major problems of mass media-led EE: (1) The ethical responsibility for both intended and unintended consequences of changes produced; (2) The insufficient theoretical explanations for such changes; and (3) The inherent following of a linear model of communication that ignores "the complexity of social change processes that require interaction, deliberation, and action by members of the social systems".

The EE research methods are also targeted to several criticisms. First, it is often difficult to validate self-reports of the effects. Second, as Entertainment-Education usually takes place within the context of a larger campaign that relies on external messages and stimuli, it is often complicated or merely possible to sort out the effects of these programs from other influences. Finally, critics have noted that mass media audiences, for example, those who have access to television, frequently constitute only small segments of the target population. The most at-risk populations may not be reached by entertainment-education (Melkote \& Steeves, 2001).

There are times that artists and scholars were questioned on how they measure the result of their research in certain ways. Some believe the researchers have to categorize their studies either in qualitative or quantitative research where they can use theoretical frameworks, surveys, and interviews or collect data to calculate the research outcomes. However, a few questions have been raised due to different characteristics and techniques of another genre of research - the creative research, since academic disciplines today have been broadened in order to provide options and spaces for everyone. After a radical period where postmodernists tried to unfold and deconstruct the binary mindset, many forms of arts have emerged and nourished academic community across the world. Artistic practitioners become the researchers meanwhile the researchers become the doers/makers/performers themselves. Many arts are not just a piece of creative work but also a process of learning and making that requires a holistic approach to organize these artistic scholarships. How can arts be researched and evaluated? What is the research license or methodology that can be practically used to conduct the study? Or even how can performing a performance can be regarded as an academic research?

\section{Practicing the Research-Researching the Practice}

Increative research field, terms like Practice-based Research, Practice-led Research and Practice as Research are much relevant and overlapped at some point, because these methodologies are the means to investigate all creative research that transmit the actual artistic practice into the written research at the end of the process. To clarify, Practice-based Research tends to claim the artistic practice as the methods, process and content - the embodiment of the research; mostly the study starts with questions or issues. Meanwhile, Practice-led Research can be defined as any creative practice, the learning process, that leads and produces new and innovative knowledge; the written text (research) can be exclusively separated from the creative work (Candy, 2006). However, in our project we focus on how theatre arts and performance can be used as a social marketing application diffusing environmental messages to teenagers. We employ both practice-based and practice-led research concepts to create a practical artistic research which also leads to new insights for the study as Smith and Deanwrote:

[I]n practice-based research the creative work acts as a form of research, whereas practice-led research is about practice leading to research insights; however, these terms are often used much more loosely. Increasingly it seems that practice as research can best be interpreted in terms of a broader view of creative practice which includes not only the artwork but also the surrounding theorisation and documentation. (Smith \& Dean, 2009) 
From this point, we utilize the concepts of Practice as Research $(\mathrm{PaR})$ as an approach to investigate our research questions in this particular project. During early 1990s, the concept of Practiceas Research has been initiated by practitioner-researchers especially in UK before this notion has reached out to other regions worldwide though PaR is nothing brandnew in scientific research field since scientific experiments can be counted as the practice in their research. Practice as Research ${ }^{2}$ is the practice that provides options for artists and performers to develop their artistic works into an organized research form. In this study, we will elaborate the concepts of PaR in performance and theatrical productions. Kershaw explains this creative research practice that "practice as research" allows practitioners (as researchers) to use the practical creative and artistic processes as their research methodologies in which the hybrid practice demonstrates "creative doing with reflexive being" in research manner. Therefore, PaR methods can be very based on the projects, topics or questions of the researcher that need to be unfolded and investigated.

$\mathrm{PaR}$ is primarily a methods-focused enterprise, though its specific projects...spring from the passions and interests of hands-on creative researchers... Inevitably though, whatever the project topic, PaR research engages specific aspects of theatre and performance as innovative comparisons between different project. (Kershaw \& Nicholson, 2011, p. 64)

According to Kershaw's explanation, there are five main aspects of theatre and performance that are the components of PaR: Starting Points, Aesthetics, Locations, Transmission and Key Issues. Since PaR does not have any fixed formula for the research methods and many times it is a project-based study, topics of the research tend to start from questions, issues related to neither individual practitioner-researcher nor society or both, so Starting Points of the research is limitless, inventive, and also expresses its originality. Aesthetics, hence, are the "creative license" of the practitioners that are expressed in their project. Since PaR project can start from anything, an absolute freedom and innovation seem to be a canvas where the researchers select any colors to exercise their creativity. Location(s) is another component that bounds all artistic pieces to gether as every genre of arts needs some "space" to be displayed or performed. For example, a performance, that is either performed indoor or outdoor, requires a performing space for the actors and audience ${ }^{3}$. Location is not only the places or spaces; it also includes "time" as well. From this, locations can be regarded as "settings" consisting of time and place. Another aspect of PaR is Transmission; Kershaw asserted "[Transmission]- the means by which any knowledge/understanding/insight it produces are communicated” (Kershaw, 2011, p. 66). Focusing on how performance is created, whether it is a traditional theatre (text-based production) or the non-traditional; content of performance will eventually be transferred and transmitted by the performers to audience via various types of communicative means such as a theatrical performance, exhibition, television broadcasting, or new media. Henceforth, the modality of the means and channels of researcher's artistic works reflects diversity of aesthetic dissemination owing to the limitless possibilities of $\mathrm{PaR}$ approaches. Lastly, it is because PaR embraces countless possibilities to start the project and gathers all diverse modes to put all the pieces together; Key Issues, therefore, derive from multiple alternatives that have been made during the process of working - the keys that helps practitioner-researchers gather stories, generate the methods, and authenticate their creative expression.

\footnotetext{
${ }^{2}$ In Melissa Trimingham's work, she wrote " $\mathrm{PaR}$ is doing itself no favours by claiming that 'all practice is research'. All practice is relevant to research but does not necessarily contribute to research untilitis subject to analysis and commentary, using a language that aims to be as clear and unambiguous as possible" (Trimingham, 2002, p. 54).

3 According to the process of theatrical communication, a performance is composed with actor, text (script, notes, and messages), audience, and space.
} 
This research project initiates from the environmental issues in Chiang Mai Province since the towns people has been affected by the airpollution due to smoke from burned forest and burned fuels on streets. Subsequently, we would like to examine whether theatre arts can become an alternative participatory media for social change. So the first question is that how we, as the communicators, can explore the communicative means that enable immediate and direct "conversations" between communicators and audience? Theatre arts has one distinctive feature is different; we propose, from other types of media - the ephemerality of the performance. Though today we all have advanced technologies supporting and aiding the artists and practitioners to broadcast and record (sometimes wirelessly) theatrical performances, it is doubtlessly true that even HD recordings are not the same thing as actually being an actual performing space with the performers since the performative vibes and dynamic energies (from both sides of the stage) vibrating in the air exist only in that particular moment when the audience is present and engaged with the story told by the performers. Moreover, during the showtime a performance lives only in that time. When it is done, it is done even if the show is performed several times. This ephemeral and transitory quality of theatrical works, thus, associates with the concept of directness and immediacy in communication process we are looking for in this research project which is also interlinked with the idea of transmission in practice as research. As Kershaw explains that transmission, per se, is how a performance has a quality to be transmitted through different types of channels. $\mathrm{We}$, too, think that the process of storytelling in this performance is built from the written text and transformed into a theatrical form. From this point, we propose that how the story is told through both verbal language and nonverbal physicality of the actors is also another process of theatrical transmission. Then, visual and audio recordings are other channels that help us document all the work in order to revise and redo the piece later on.

Secondly, it is very crucial to include the concept of Theatre for Social Change ${ }^{4}$ in the working process as, we argue, it can be used to raise environmental awareness among teenagers in high school. To explain, this theatrical performance enables the audience to receive messages from the performers through a direct communication where performers and audience were interchanging their status as message senders and receivers at the same time. The process of exchange offers the participatory attribute of direct communication via theatrical performance. Referring to Victor Turner's anthropological notion of liminality, he asserts that in any ritualistic space where communal participants are celebrating the event, there is a threshold moment in which participants are no longer the members of that particular community but they take performative roles such as the shaman, spiritual dancers, or ritual members. Similarly, the liminal phase can be created during the performance, because presentational style ${ }^{5}$ that allows the performers speak to the audience directly and blur the lines between performing (acting) and an actual conversing with other people in the same performative space. The roles of them (both performers and audience) in this dramatic and ritualistic moment are blurred. As it is mentioned above the (message) sender and receiver switch their status back and forth in this liminal phase. Therefore, the real conversation is established between these two groups of people; they were actually

\footnotetext{
${ }^{4}$ T. Prentki and Sheila Preston (referred in Thornton 2012) defined Theatre for Social Change as a theatrical approach used to make changes in society. Thornton added that this conceptualization emerges from people believing that their society needs some changes and theatre arts can genuinely deliver critical thoughts and encourage the audience to think and do something about it. However, with complicated methods Theatre for Social Change can not be utterly called "traditional" dramaticart; it can be categorized as a genre of applied theatre which embodies various ways of forming and telling stories. For this reason, Theatre for Social Change provides opportunities for artists and scholars to create artistic works with their contemplative remarks (Damrung, 2004).

${ }^{5}$ For theatre arts, there are two distinctive styles of dramatic presentation: realistic (representational) and anti-realistic (presentational or sometimes it's called theatricalism).
} 
communicating in both verbal and nonverbal forms. The awareness of social, in the same token, is brought into this discussion between both parties.

\section{Devising the Research}

Another aspect that needs to be unfolded in this paper is that our PaR project endorses "Devised Theatre" as the core of how we embodied three significant directions of the performance: finding, building and telling story. Devised theatre is derived from the idea that theatre should not be fallen into only the "traditional" theatrical conventions that high light the hierarchical relations of the director, playwright, actors and the crews. Therefore, it is an alternative for theatre makers to create a democratic atmosphere while they all are working altogether as in one position — the devisees. Alison Oddey explained in her book:

Devised theatre is not always in contradistinction to "straight" theatre. Devised work is a response and a reaction to the playwright-director relationship, to text-based theatre, and to naturalism, and challenges the prevailing ideology of one person's text under another person's direction. Devised theatre concerned with the collective creation of art (not the single version of the playwright), and it is here that the emphasis has shifted from the writer to the creative artist. (Oddey, 1996, p. 4)

Many devised theatre practitioners believe that this working system allows them to fully express their creativity that includes all voices of the group members through various types of dramatic presentation style. The integrated use of media and communicative means are also another distinctive characteristic of devised theatre. She added that this concept can start with limitless possibilities of artistic collage works such as images, poem, songs, painting, objects, and indeed dramatic expressions through the performer's body. "[T]he precise nature of the end product is unknown", Oddey explained.

From the starting point, we began with the primary premises on environmental issues resulted from deforestation and burnt fuels from vehicles. We believe that working on these issues will significantly nurture and shape how the devisees perceive the world in different way. The "smog" problem in Chiang Mai is nothing new to the people. Everyone has been talking about this and trying to find many solutions to solve this, but unable to do it. For example, we still drive our cars everyday and try to ignore the smoke coming from the forest by using the mask to protect ourselves from air pollution. Do we need to stop using cars or tell people to stop burning woods? We believe that the change will start from one's self first, then it will inspire the other to make change too. In the later part of this paper, we will elaborate how our theatre for social change endorses the concept of sustainability on environmental development. So the next question is "how can we do that?".

\section{Collaging the Ideas-Creating the Arts}

Together with PaR methods, we locate our second project premise on collaging the work that is derived from the devisees who are actually college students from Chiang Mai University. There is no audition or casting call to "select" the performers to participate in this project; rather we invited all students who share their interest on theatrical training and dramatic experiments dealing with problems in society. We propose that the core of creating a devised work is not about having the existed script, performing it and observing the reaction from the audience after the show but this collective collaboration system in which brainstorming, talking, listening and exchanging ideas is the essence of devising a community where trust and the sense of communality are established among the participants. Then, the actual freedom in creating artistic (and democratic) work begins. We divided our working process into three main sessions: training, devising, and rehearsing. The first four days we tend to call it "finding the self and the story". The purpose of this workshop 
is to equip the participants with the tools to help them express their thoughts through various channels such as body movement and expression, writing, and oral interpretation (reading/narrating the text).

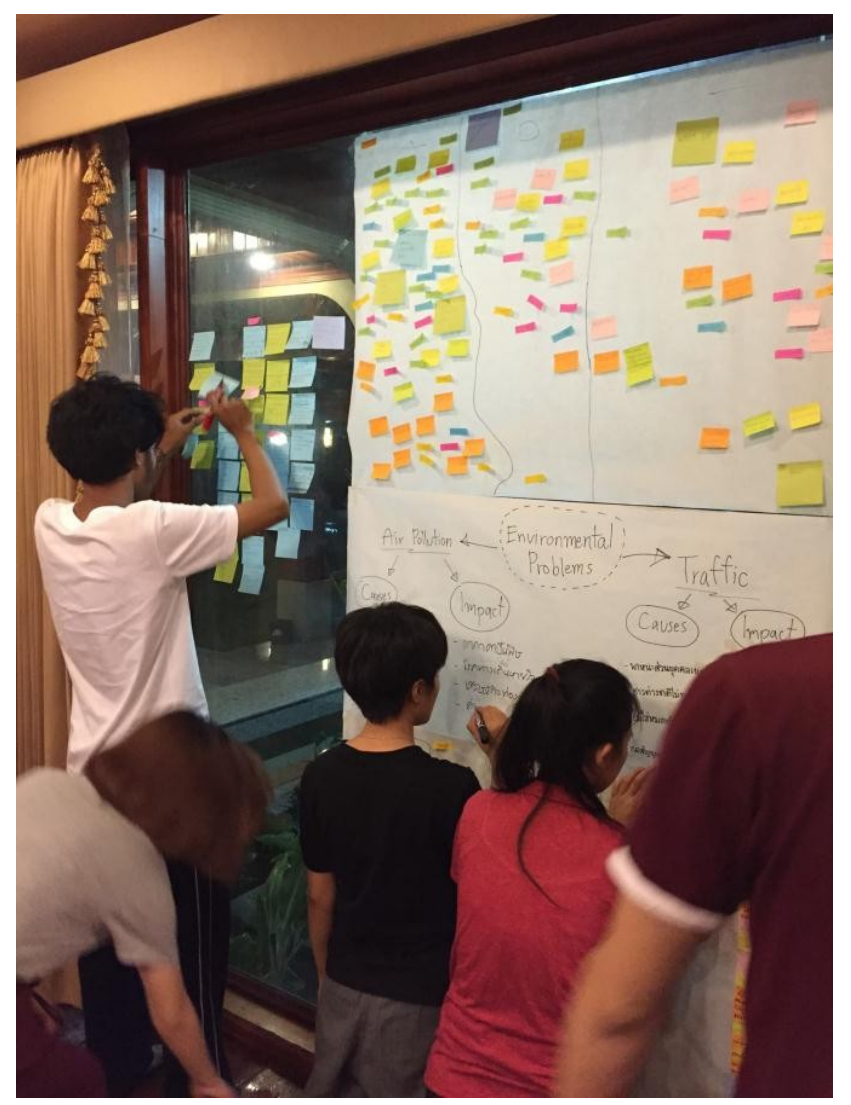

Figure 1. The devisees are brainstorming the comcepts of the performance "A Breath for Tomorrow".

During the body training session, we used Anne Bogart's Viewpoints techniques ${ }^{6}$ to work with the performers. All the aspects of Viewpoints (time, space, and composition) emphasize on surrender, possibility, choice and freedom, growth, wholeness and most importantly spontaneity or in other words improvisation. These qualities they employed during the workshop echo all significant features of devised theatre. To create, as we mentioned it above, communality and togetherness one must learn to acknowledge other people's voices; it is how democratic working process is sustained while creating the work. In our session, the devisees began with brainstorming ideas - putting them on post-it notes. Here, this is, per se, the most fundamental and crucial point of finding the story for this performance. It is very necessary to set some rules during this process; “don't think or stop writing". Free writing allows them to unblock all the frameworks and rules they have learned from all writing classes including playwriting class for drama students. We (as drama students and teachers) used to be taught to put thoughts and things in order according to the "structure" of the dramatic work. Still, all the outlines are primarily crucial; meanwhile, there should be some space to exercise their imagination and freedom. And after sorting ideas and keywords into groups, the devisees had to select key issues that fit with the theme of environmental issues and sustainable development.

\footnotetext{
${ }^{6}$ According to Bogart, Viewpoints is the technique to train performers (bodily), building ensemble, and creating movement for the stage (Bogart \& Landau 2005, p. 7). Here, I would like to assert that not only movements are created on stage by the performers but the kinesthetic relationship between them also creates compositions and images.
} 
Along these lines of freedom and creativity, selection is another method to shape abstract concepts into bigger picture of what they are about to create in the next phase. It is very pivotal to make it clear that the period of finding the story requires improvisation to extract the concepts, but to build the piece one needs to decide what and how to embody the tiny bits of images into one complete image of a collage performance. In the final reflection, they conceptualized how to tell the story in the form of body movement and expression, poetry reading and role play. Here's an interesting point, our attempt to create participatory dialogues among the devisees can be seen not only through how they exchanged their opinions but also through how they listen to other performers' bodies when they are rehearsing the piece. This is because Viewpoints, unquestionably, demands mutual kinesthetic responses among the group members; when someone open their awareness, all movements and nonverbal dialogues will be connected as a whole group moving in the same rhythm and motion. As Bogart wrote in her book:

Through Viewpoints we learn how to listen with our entire bodies and see with a sixth sense. We receive information from levels we were not even aware existed, and begin to communicate back with equal depth. (Bogart, 2005)

\section{"We Think, Therefore, We Perform"-Engaging the Participatory Devices With the Community}

After all the experiments we (the devisers and devisees) have undergone and experienced, it is the time to push the our performance - as we call it "A Breath for Tomorrow", on this onward journey that actually engages our work with the high school community in Chiang Mai province. We went to Yupparaj Wittayalai School, a highly renowned school located in the heart of Chiang Mai, during summer with the hope that this devised piece would actually raise environmental awareness among high school students. However, it is truly challenging for us to do this in public with the fear that people in general might not have seen any kinds of theatrical performances before hand. With the students around 80 people filled in an empty classroom which is eventually set into a performing space for us, the performers successfully created the realm of a "make-believe" space where young audience were fully drawn to the theatrical occurrence happening in front of them. There is one scene which is notably remarkable in terms of participatory relationship between performers and audience; it is when the actors were suffocated under the plastic wrap signifying how they're walled in by the smoke coming from the forest and carson the street.

Afterward, we arranged a post-talk session to hear all feedbacks and reflection from the audience by giving them post-it notes and encouraging them to decode the performance in their own words. Consequently, the result is more likely shown in a stylized manner when the devisees truly understand that making theatre for social change is not an environmental campaign asking the audience to make change. On the contrary, to make a clear statement and demonstrate their political standpoint, the performers took two roles: the speakers and the listeners. Meanwhile, they were on the stage that is the space of their voices, they also absorbed the communicative energy from the audience. Further, the post-it notes reflect that the audience do not only understand the environmental messages embedded in the performance, they were also able to provide insights on how they can solve the problems with realistic solutions, a practical and sustainable actions. One of the students stated that in order to make change, they have to start with themselves first. Our messages do not only raise environmental awareness among teenagers just in physical and psychological way but it reaches the process of learning through spiritual dimension of the high school students as well. 


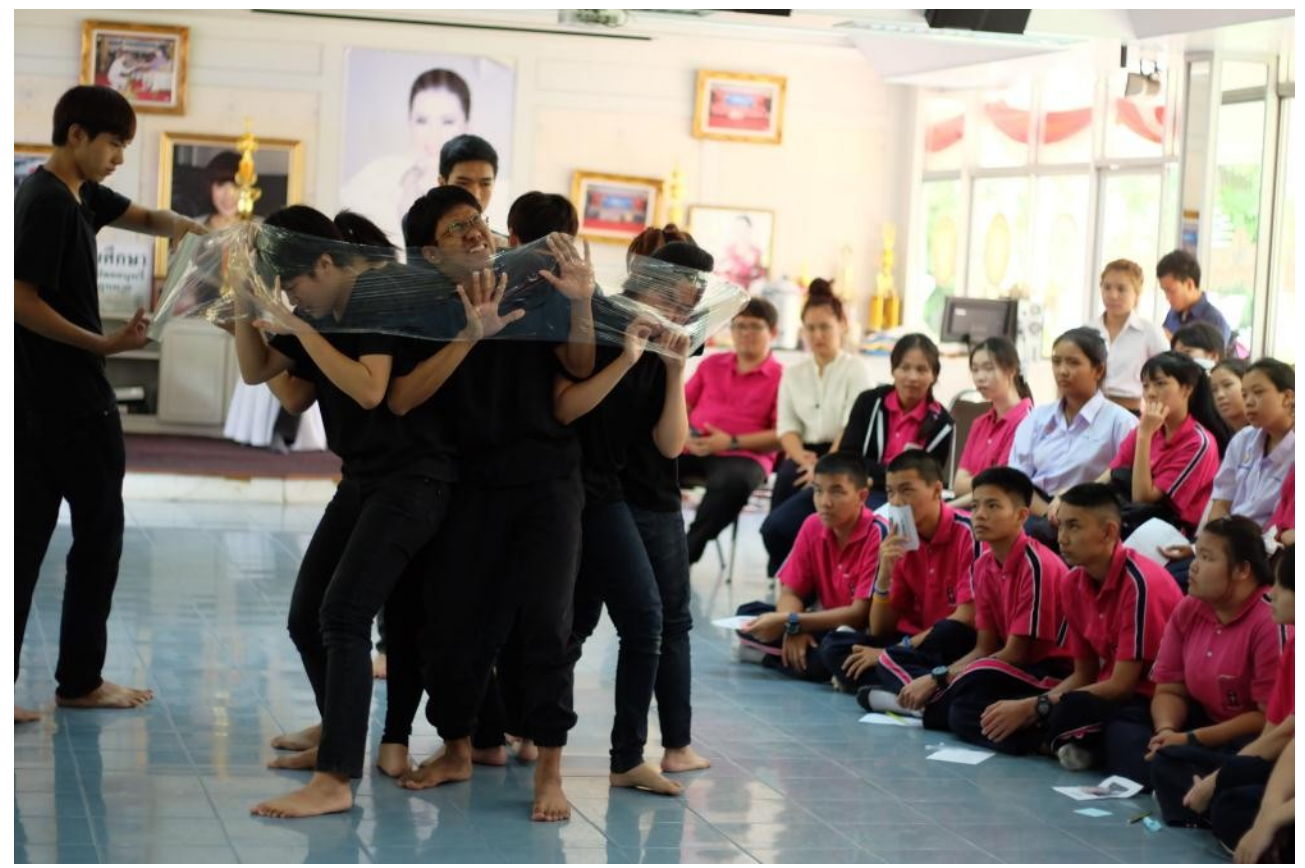

Figure 2. Ascene from "A Breath for Tomorrow" portraying how towns people are suffocated from environmental problems.

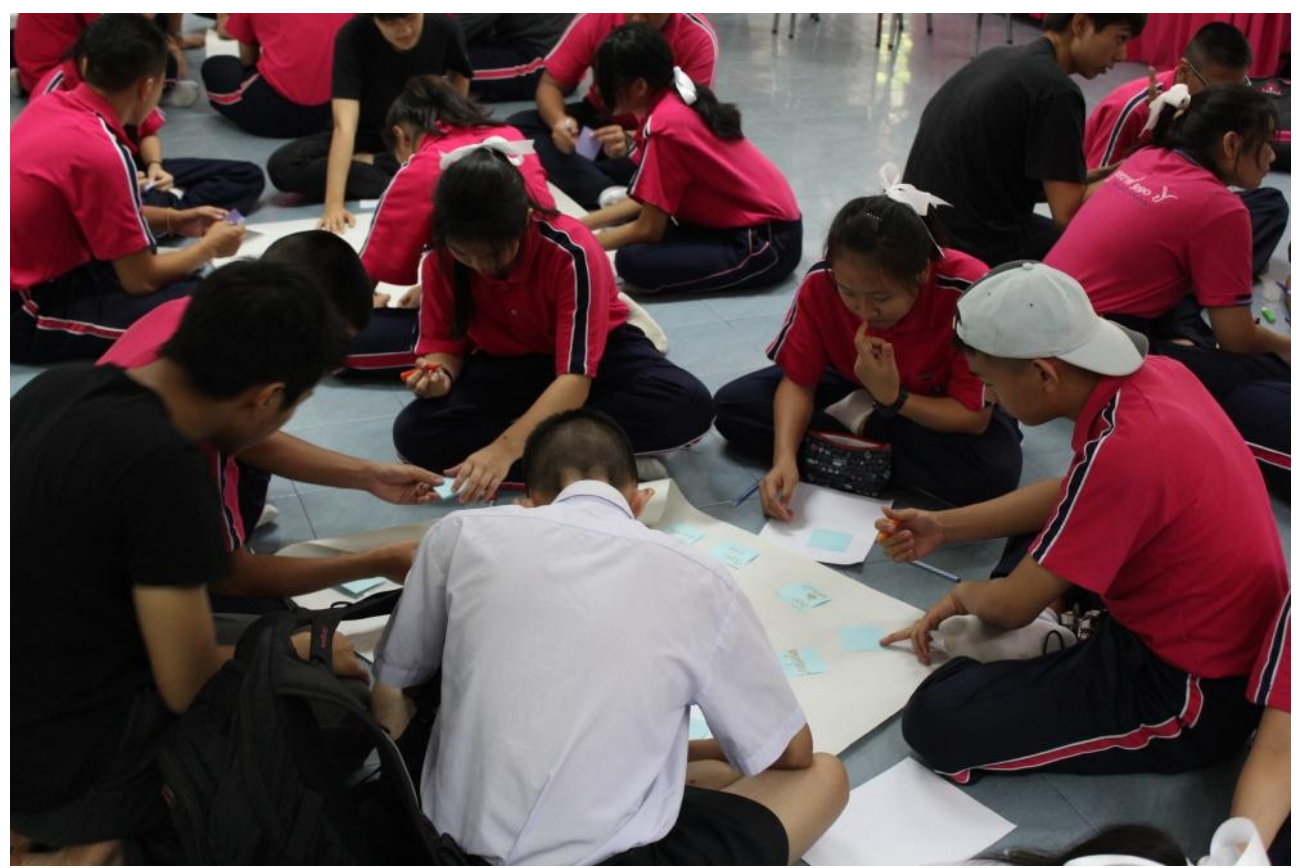

Figure 3. During the post-talk session, the audiences are exchanging their perspectives towards the problems.

From devisees to devisers, this research reveals that theatrical arts can be utilized as participatory media for social change as indicated in three fold: (1) The performers switch their roles as performers to devisers who encourage high school students to be development communicators. This indication is associated with participatory communication as it requires much more imagination, preparation, and hardwork to have the dialogical learning (Servaes \& Malikhao, 2005); (2) This project provide a space to the voiceless in the community to voice out their opinions resulted from social problems in their daily life. This phenomenon 
reflects that when community members actually engage themselves with the problem, the sense of belonging and ownership towards those particular problems are established; and (3) This project on participatory communication for social change recognizes the participants, including the performers and their audience, as the nucleus of development. It is a philosophy of sustainable development that aims to cultivate this notion and stimulate the people in Chiang Mai community at large to be active in lifelong learning and societal improvement. The "youth power" will lift up the spirits of micro community to cherish their own culture and local wisdom while they can sustain a balanced ecology.

\section{References}

Andreason, A. R. (1995). Marketing for social change. SanFransisco, CA: Jossey-Bass.

Beltrán, L. R. (1976). Alien premises, objects, and methods in Latin American communication research. Beverly Hills: Sage.

Bogart, A., \& Landau, T. (2005). The viewpoints book: A practical guide to viewpoints and composition. New York: Theatre Communications Group.

Candy, L. (2006). Practice based research: A guide. CCS Report, 1, 1-19.

Damrung, P. (2004). Theatre arts for children. Bangkok: Chulalongkorn University Press.

Dinan, C., \& Sargeant, A. (2000). Social marketing and sustainable tourism: Is there a match? International Journal of Tourism Research, 2, 2-14.

Kershaw, B., \& Nicholson, H. (2011). Research methods in theatre and performance. Edinburgh: Edinburgh University Press.

Maibach, E. (1993). Social marketing for the environment: Using information campaign to promote environmental awareness and behavior change. Health Promotion International, 8(3), 209-224.

Melkote, S. R., \& Steeves, H. L. (2001). Communication for development in the third world-Theory and practice for empowerment. Thousand Oaks, CA: Sage.

Oddey, A. (1996). Devising theatre: Apractical and theoretical handbook. London: Routledge.

Papa, M. J., Singhal, A., Law, S., Pant, S., Sood, S., Rogers, E. M., \& Shefner-Rogers, C. L. (2000). Entertainment-education and social change: An analysis of prosocial interaction, social learning, collective efficacy, and paradoxical communication. Journal of Communication, 50(4), 31-55.

Servaes, J., \& Malikhao, P. (2005). Media and global change: Rethinking communication for development. Teborg, Sweden: Ordicom.

Singhal, A., \& Rogers, E. M. (1998). Television soap operas for development in India. Gazette.

Singhal, A., \& Rogers, E. M. (1999). Entertainment-education: A communication strategy for social change. Mahwah, NJ: Lawrence Earlbaum.

Smith, H., \& Dean, R. T. (2009). Practice-led research, research-led practice in the creative arts. Edinburgh: Edinburgh University Press.

Trimingham, M. (2002). A methodology for practice as research. Studies in Theatre and Performance, 22(1), 54-60.

Waisbord, S. (2000). Family tree of theories, methodologies and strategies in development communication: Convergences and differences. New York: Rockefeller Foundation Report. 